\title{
Predicting Teacher Anxiety, Depression, and Job Satisfaction
}

\author{
Kristen Ferguson \\ Nipissing University \\ Lorraine Frost \\ Nipissing University \\ David Hall \\ Nipissing University
}

\begin{abstract}
This study investigates predictors of anxiety, depression, and job satisfaction in teachers in northern Ontario. Using data from self-report questionnaires, factor analysis and multiple linear regression were performed to determine which sources of stress predict stress-related symptoms among teachers and to explore job satisfaction as predicted by: stress, depression, anxiety, years of teaching experience, gender, grade level assignment and position (part-time vs. full-time). The results indicate that workload and student behaviour were significant predictors of depression in teachers in the study. Workload, student behaviour, and employment conditions were significant predictors of anxiety. In addition, stress and depression had a significant and negative impact on job satisfaction. Years of teaching experience was a significant and positive predictor of job satisfaction. Anxiety, gender, grade level, and position were not statistically significant predictors of teacher job satisfaction. Therefore, efforts made to improve workload, student behavior, and employment conditions may lead to reduced stress among teachers and thus lower levels of depression and anxiety. These results may provide guidance for teachers and administrators, as well as inform teacher retention efforts and attempts to improve teacher job satisfaction.
\end{abstract}

Kyriacou (2001) defines teacher stress as "the experience by a teacher of unpleasant, negative emotions, such as anger, anxiety, tension, frustration or depression, resulting from some aspect of their work as a teacher" (p. 28). Teacher stress appears to be prevalent in the teaching profession. In their pivotal study, Kyriacou and Sutcliffe (1978) found that approximately 20\% of comprehensive school teachers in England found teaching to be very stressful or extremely stressful. Borg and Riding (1991) found even higher results in the stress levels of Maltese teachers, with almost 34\% of Maltese teachers rating their jobs as either very stressful or extremely stressful. A study of New Zealand intermediate teachers by Manthei and Gilmore (1996) found that just over 26\% of teachers felt that teaching was either very or extremely stressful. 
Canadian teachers are also experiencing high levels of stress. According to the Canadian Teacher's Federation (2001), six in ten teachers surveyed find that their job is more stressful now than it was two years ago. The 2006 Ontario College of Teachers annual survey, entitled The State of the Teaching Profession, found Ontario teachers are experiencing high levels of stress, with $13 \%$ of teachers indicating that they feel stressed all the time, compared to only $7 \%$ of workers in the general public (Jamieson, 2006). The Ontario College of Teachers also surveyed education graduates of the year 2001 and found that the second highest reason for teachers leaving the profession was because working conditions were too stressful (McIntyre, 2006).

Some researchers have investigated how physical and emotional symptoms of stress are related to teacher stress. Kyriacou and Sutcliffe (1978), for example, found a positive correlation among 17 symptoms of stress and self-reported teacher stress. The highest correlation $(r)$ was between the symptom of frustration and teacher stress, having a correlation coefficient of $r=.610$. Other very high correlations found by Kyriacou and Sutcliffe existed between teacher stress and feeling very tense $(r=.600)$ and exhaustion $(r=.525)$. Manthei and Gilmore (1996) also found that $31.4 \%$ of teachers indicated a high to severe level of disturbance in regard to their general health. While Manthei and Gilmore do not correlate these disturbances with teacher stress, they imply that "the score indicates a level of anxiety and tension" (p. 16). While Kyriacou and Sutcliffe and Manthei and Gilmore's work explores teacher stress and its relationship to possible manifested symptoms of teacher stress, a review of the literature, however, provides scant data about factors that cause teacher stress as predictors of anxiety or depression. Studies of occupational stress in other fields do reveal some research into stress predictors of depression. Baba, Galperin, and Lituchy (1999), for example, found that burnout is a predictor of depression among nurses in the Caribbean. Revicki, Gallery, Whitley, and Allison(1993) found that work-related stress is a significant predictor of depression in second-year emergency medicine residents. There appears, however, to be little research published about stress factors that may predict anxiety.

According to the Ontario College of Teachers, "there are growing signs of unease in the profession" (Browne, 2007, p. 55). The Ontario College of Teacher's annual "State of the Teaching Profession" phone survey, which contacted more than one thousand teachers, found that "only 78 per cent are happy with the job they are doing, while $70 \%$ are satisfied with their school and 73 per cent are satisfied with the profession as a whole" (Browne, p. 55). According to the College, this is a significant change from the results of the 2006 annual survey (Browne, Ibid.). In the report on the annual survey in the Ontario College of Teacher's magazine, Professionally Speaking, Browne discusses some possible reasons for this change in teachers' job satisfaction. Browne speculates that the higher satisfaction rates in 2006 may indicate an era of peace that was created by an earlier change in provincial government that resulted in higher salaries and more resources (Ibid.). Browne also notes that the decrease in job satisfaction in 2007 may also reflect the change in demographics in the teaching profession since there are many young teachers and the first few years of teaching may have a sharp learning curve (Ibid.). 
A review of the literature reveals an abundance of research that investigates relationships between certain job factors and teacher job satisfaction. For example, one focus of research in teacher job satisfaction has been on a principal's leadership style and school climate (Evans \& Johnson, 1990; Littrell, 1994; Taylor \& Tashakkori, 1995). The literature, however, is limited in the area of predictors of teacher job satisfaction. One study which does examine predictors of teacher job satisfaction is the research by DeFrank and Stroup (1989). DeFrank and Stoup surveyed teachers in a school district in Texas and found that job stress was the strongest predictor of teacher job satisfaction. A more recent study which investigates predictors of job satisfaction was the work of Kim and Loadman (1994). Kim and Loadman surveyed practicing classroom teachers selected from the graduation lists from ten universities in the United States; 2054 teachers completed the survey. Kim and Loadman found seven statistically significant predictors of teacher job satisfaction, including salary, opportunities for advancement, professional challenge, professional autonomy, working conditions, interaction with colleagues and interactions with students. In other occupations, research has also been undertaken to investigate predictors of job satisfaction. In nursing, for example, predictors of job satisfaction include stress (Flanagan, 2006; Rout, 2000), perceived relations with co-workers (Decker, 1997), social support from the supervisor, reward, and control over work (Gelsema et al., 2006). Thus, while there has been some research conducted in the area of predictors of teacher job satisfaction, clearly more research, particularly with Canadian teachers, is needed.

Teacher job satisfaction may be a critical component for teacher retention in Ontario. The Ontario College of Teachers reports that in 2005, 8\% of 2001 teacher-education graduates were no longer members of the College (McIntyre, 2006). These participants were separated into two groups: those who intend to return to the teaching profession and those who have left. The response to the survey item "satisfaction with teaching experience" differed significantly between the two groups: the mean score for those who have left the profession on this item was 2.54 and the mean for those who intend to return to the profession was 3.62 (" $1=$ strong dissatisfaction or low support, $5=$ strong satisfaction or high support," McIntyre, p. 49). According to the report, for those that have left the profession, "teaching appears to have been a negative experience for them" (McIntyre, p. 50).

The purpose of our research was twofold. First, we sought to identify which occupational stress factors predict teacher anxiety and depression. Second, we wanted to identify significant predictors of teacher job satisfaction. We believe our research is unique because most research on teacher stress examines levels of stress, stress factors, and symptoms of stress, but does not examine the relationship among these factors so that statements about predictors of teacher anxiety and depression can be made. We also feel that our research into the predictors of job satisfaction of northern Ontario teachers is important as it contributes to the dearth of research on this topic in Canada.

\section{Theoretical Framework}

We approached this study on stress using the theory of psychological distress. A life without stress is not plausible or desirable. In reasonable doses, stress is a 
motivator and may enhance work performance (Selye, 1976). On the other hand, in unreasonable amounts, stress can become distress (Cedoline, 1982). Psychological distress is defined as a negative event over which a person has no control (Mirowsky \& Ross, 2003). Teachers encounter many potentially negative events in their everyday professional lives over which they have little or no control or power. Students' behaviours and lives outside of school, school board and government initiatives, job security, and promotion are just a few examples of situations over which teachers may have little or no control. Thus, negative events over which teachers have little or no control may create distress. According to Mirowsky and Ross, psychological distress takes two forms: depression and anxiety.

Also framing our study is Herzberg's theory of motivation to work (Herzberg, Mausner, \& Snyderman, 1959). Following this theory, certain factors are motivating forces that enhance job satisfaction; other factors (called hygiene factors) may cause teachers to be unsatisfied with their jobs. Motivation factors, which lead to job satisfaction include achievement, recognition, the work itself, responsibility, and the opportunity for growth. Hygiene factors, which lead to dissatisfaction if not addressed, include supervision, interpersonal relations, salary, and company policies. The removal of a dissatisfying factor, however, will not necessarily provide satisfaction in and of itself; and, conversely, when job satisfaction increases, dissatisfaction will be unaffected. Nias (1981) tested Herzberg's theory of job satisfaction on a sample of 100 teachers and found that the Herzberg's theory of motivation and hygiene factors to be true with the results of her study of teacher job satisfaction. We believe, therefore, that for teachers to be satisfied with their jobs hygiene factors must be addressed and also that motivation factors must be present.

\section{Methodology}

\section{Instrument}

A self-report teacher stress questionnaire was developed from a review of previous research by Kyriacou and Sutcliffe (1978), Fimian (1984), Borg and Riding (1991), Manthei and Gilmore (1996) and the British Columbia Teachers' Federation (cited in Edudata, n.d.). Our research analyzed data from a number of sections of the questionnaire. In the first section, respondents rated their stress levels on 46 specific stress sources through the question, "As a teacher, how great a source of stress are these factors to you?" on a 5 interval scale ranging from no stress to extreme stress. General stress was measured by the following question: "In general, how stressful do you find being a teacher?" on a 5-point scale of not at all stressful, mildly stressful, moderately stressful, very stressful, and extremely stressful. In the second section of the questionnaire, respondents reported the frequency of fifteen stress-related physical and psychological symptoms they experienced during the school year with the question "Please estimate how frequently during the school year you experience the following:" on a 5 interval scale ranging from never to many times a day. Respondents were then asked to rate their job satisfaction with the following question: "In general, how satisfied are you with your job as a teacher?" on a 5-point scale ranging from very dissatisfied to very satisfied. Finally, the respondents were also asked 
multiple-choice questions about demographic information regarding gender, age, years of experience in teaching, grade level, and current assignment. In addition, there was an open comments section at the end of the survey for respondents to comment on any aspect of the questionnaire.

A focus group of teachers pretested the questionnaire. These teachers had a variety of teaching backgrounds and included males and females as well as elementary and secondary teachers. Changes and modifications of the instrument were made using the feedback from the focus group. The instrument proved to be very reliable. Cronbach's alpha for the questionnaire was calculated and found to be .951 .

\section{Sample}

The sample for our study consisted of teachers from northern Ontario enrolled in Nipissing University's inservice courses in winter session of 2005. To find teachers who lived in northern Ontario, we identified those teachers whose postal codes began with the letter "P." This postal code region covers a large area, including 25 different Catholic, public, English, and French school boards as well as many band-controlled First Nations schools (Ministry of Education, n.d.). Thus, our method of using teachers enrolled in in-service courses allowed us to draw a sample of teachers from northern Ontario, working in a variety of school boards and settings.

Five hundred sixty-six teachers from Nipissing University's database had postal codes that began with the letter "P," were enrolled in the winter session of additional qualification courses, and, thus, were mailed questionnaire packages. To encourage a high response rate, potential participants were also mailed a reminder notice. A total of 274 questionnaires were completed and returned, which gives us a response rate of $48 \%$.

\section{Results}

The research strategy pursued in the analysis had two distinct phases. In the first phase, we factor analyzed survey responses to 15 survey items measuring stress symptoms and the 46 indicators measuring stress sources with the goal of condensing these into a small number of more abstract concepts. In the second phase, we used the results of the factor analysis to develop multiple linear regression models. First, we created a model that identifies which sources of stress are salient predictors of stress-related symptoms among teachers. We then used the index variables derived from our factor analysis, along with other plausible covariates, in order to develop another multiple linear regression model that identifies salient predictors of teacher job satisfaction.

\section{Measuring Stress Symptoms: Depression and Anxiety}

Factor analysis is an established multivariate technique for determining which specific (measured) variables in a data set can be combined to form coherent subsets of general, latent (underlying) variables, known as factors. The major assumption of factor analysis is that factors represent meaningful abstract constructs that explain correlations within the larger set of measured variables. Insofar as factors are interpretable as abstract constructs, factor analysis is a 
powerful tool for condensing a large number of variables into a smaller number of theoretically and empirically useful constructs (Tabachnick \& Fidell, 2007).

The results of a preliminary factor analysis of the 15 items measuring physical and psychological stress symptoms confirmed the suitability of the items for factor analysis, pointed to two relevant dimensions of stress symptomology, and uncovered two questions that were "factorially complex" or were correlated with both factors. These two questions ("frustration" and "heart beating fast") were dropped from the subsequent analysis, which specified a two factor solution using Principal Axis extraction with Promax rotation.

The results of the subsequent factor analysis are shown in Table 1, which displays the Pearson correlations (factor loadings) of each stress symptom item with its respective factor. The first factor (Factor 1) reflects a set of symptoms that are connected to Depression since questions pertaining to the frequency of depression, inability to cope, and frequency of exhaustion loaded very highly on this construct. By the same token, questions involving the frequency of feelings of "anxiety" and "nervousness" were strongly correlated with the second factor (Factor 2), and this factor was seen as measuring Anxiety. Importantly, the two stress symptom factors were only moderately correlated $(r=.601)$ which suggests that these factors capture more or less distinct dimensions of stress symptoms suffered by teachers.

Table 1: Factor pattern matrix of physical and psychological symptoms of teacher stress.

\begin{tabular}{ccc}
\hline Symptoms of Stress & Factor 1 & Factor 2 \\
\hline Depression & .784 & \\
Unable to cope & .708 & \\
Exhaustion & .613 & \\
Sadness & .476 & \\
Increased blood pressure & .467 & \\
Very angry & .461 & \\
Difficulty sleeping & .448 & .851 \\
Headaches & .448 & .756 \\
Cold sweats & .419 & .602 \\
Anxiety & & .578 \\
Nervousness & & \\
Tense & & \\
Panic & & \\
\hline
\end{tabular}

Measuring the Sources of Teacher Stress: Workload, Student Behaviour, Employment Conditions, and Administration

To operationalize the predictor variables for our model, a preliminary factor analysis of the 46 indicators measuring the intensity of various sources of stress for teachers uncovered four abstract concepts. As well, we discovered nine questions that were "factorially complex" (were correlated with more than one factor), and consistent with accepted practice we dropped these nine questions 
from the subsequent factor analysis which specified a four factor solution using Principal Axis extraction with Promax rotation. The results of our factor analysis of the remaining 37 questions (in Table 2) show the factor loadings (correlations) for each source of stress with its associated factor. The first factor (Factor 1) summarizes a set of indicators involving Workload since items measuring stress from "too much work," "not enough time to do work," "lack of time for marking," and "increase in workload" have the strongest correlations with this dimension. Factor 2 summarizes a cluster of items connected to Student Behaviour as a source of stress in view of the fact that the intensity of stress from "poorly motivated students," "disruptive student behaviour," and "students' attitudes towards work" had the highest loadings on this construct. The same logic led to our designation of Factor 3 as Employment Conditions given that items such as "poor promotion opportunities" and "job security" had the highest correlations with this factor. Finally, we labeled Factor 4 as Administration because the three most important questions linked to this dimension revolved around the respondent's relationship with school administration. As with the factor analysis of the symptoms of stress, the four factors that summarized the sources of stress were not highly correlated (maximum $r$ of .480) which implies that the factors operationalized four general sources of stress for educators.

One of the most useful statistics generated from factor analysis are factor coefficients. These coefficients represent "weights" that reflect the unique contribution of each indicator to a factor. More important, the weighted sum of scores on a set of items produce a continuous score on each factor for each respondent. The great value of factor scores is that they provide a continuous index that operationalizes each salient construct. We developed a total of six such factor indices: two indices measured the dependent variables of Depression and Anxiety, and four indices measured the independent variables of Workload, Student Behaviour, Employment Conditions, and Administration.

\section{Results of Regression Model 1: Sources of Teacher Depression}

The second phase of our research strategy involved using the results of our factor analysis to develop multiple linear regression models that might identify which sources of stress are salient predictors of stress symptoms in teachers. To this end, the first regression model summarized in Table 3 shows the results of regressing the four independent variables (Workload, Student Behaviour, Employment Conditions, and Administration) on the dependent variable of Depression. Regression diagnostics available in SPSS Regression revealed that the variables used in our models were consistent with the parametric assumptions of multiple linear regression. Two cases were flagged as multivariate outliers (extremely deviant cases) and dropped from subsequent analysis to avoid biasing the model.

Looking at the overall fit of the model, the multiple correlation coefficient between our four sources of stress and teacher depression was a moderate, statistically significant .490 . As a consequence, respondent scores on the indices measuring Workload, Student Behaviour, Employment Conditions, and Administration as sources of stress accounted for about $1 / 4$ (24\%) of the variability in respondent scores on Depression. Although our independent variables have substantially improved our ability to predict depression in 
Table 2: Factor pattern matrix of the sources of teacher stress.

\begin{tabular}{|c|c|c|c|c|}
\hline Sources of stress & Factor 1 & Factor 2 & Factor 3 & Factor 4 \\
\hline Too much work & .961 & & & \\
\hline Not enough time to do work & .957 & & & \\
\hline Lack of time for marking & .819 & & & \\
\hline Increase in workload & .803 & & & \\
\hline Balancing home and work & .791 & & & \\
\hline Inadequate preparation time & .719 & & & \\
\hline Paperwork & .650 & & & \\
\hline Lack of time to assist students & .638 & & & \\
\hline Completing report cards & .631 & & & \\
\hline Taking courses while working & .532 & & & \\
\hline Split-grade classrooms & .515 & & & \\
\hline Class size & .445 & & & \\
\hline Accountable for student & .413 & & & \\
\hline Shortage of teaching materials & .412 & & & \\
\hline Completing IEPs & .387 & & & \\
\hline Curriculum changes & .379 & & & \\
\hline Poorly motivated students & & .879 & & \\
\hline Disruptive student behaviour & & .765 & & \\
\hline Students' attitude towards work & & .732 & & \\
\hline Student misbehaviour & & 619 & & \\
\hline Lack of social respect for & & .485 & & \\
\hline Undeserved criticism of teachers & & .477 & & \\
\hline Mixed student ability & & .472 & & \\
\hline Maintaining class discipline & & .420 & & \\
\hline Student difficulties at home & & .351 & & \\
\hline Lack of recognition of teachers & &, 329 & & \\
\hline Poor promotion opportunities & & & .657 & \\
\hline Job security & & & .561 & \\
\hline Lack of professional & & & .557 & \\
\hline Inadequate salary & & & .484 & \\
\hline Extra-curricular responsibilities & & & .384 & \\
\hline Relations with support staff & & & .377 & \\
\hline Relationship with other teachers & & & .356 & \\
\hline Relationship with principal/VP & & & & .842 \\
\hline Lack of communication from & & & & .825 \\
\hline Attitudes/Behaviour of principal & & & & .823 \\
\hline Lack of input in decision-making & & & & .407 \\
\hline
\end{tabular}


teachers, examining the model parameters in Table 3 reveals that only Workload and Student Behaviour had statistically significant regression coefficients. In particular, the unstandardized regression coefficient for Workload of .226 tells us that as respondent scores on the factor index measuring workload as a source of stress increase by one unit, their scores on the index measuring teacher depression increase by .226 units (holding constant the effects of the other predictors). Likewise, as respondent scores on the variable measuring Student Behaviour increase by one unit, their scores on the variable for Depression, net of the other predictors in the model, increase by .154 units. Employment Conditions and Administration made negligible contributions to the model predicting Depression and their regression coefficients were statistically insignificant. The standardized regression coefficients demonstrate the relative importance of each predictor, and confirm that specific issues such as that too much work, inadequate time for teaching and marking, and poor student motivation, attitudes toward school work, and classroom behaviour are key predictors of depression among teachers.

Table 3: Multiple regression: Impact of workload, student behaviour, employment conditions, and administration on teacher depression.

\begin{tabular}{ccc}
\hline Source of stress & $\begin{array}{c}\text { Unstandardized regression } \\
\text { coefficient }\end{array}$ & $\begin{array}{c}\text { Standardized regression } \\
\text { coefficient }\end{array}$ \\
\hline Workload & $.226^{*}$ & $.251^{*}$ \\
Student behaviour & $.154^{*}$ & $.167^{*}$ \\
Employment conditions & .110 & .114 \\
Administration & .080 & .086 \\
Constant & $2.123^{*}$ & \\
\hline
\end{tabular}

$* p<.05$. Multiple $\mathrm{R}=.490$, Multiple R-squared $=.24$

\section{Results of Regression Model 2: Sources of Teacher Anxiety}

Our second regression model (see Table 4) regressed the four independent variables on the dependent variable Anxiety. Once again, diagnostics available in the SPSS Regression program confirmed that the linear regression assumptions regarding linearity, normality, homoscedasticity, independence, and multicollinearity were satisfied. To avoid biasing the regression parameters, three cases identified as multivariate outliers were excluded from the Anxiety model.

With respect to the model fit, the multiple correlation coefficient between the four sources of stress and anxiety was a moderate and statistically significant 491. Similar to the results from our model for teacher depression, this tells us that Workload, Student Behaviour, Employment Conditions, and Administration explain nearly $1 / 4(24 \%)$ of the variability in respondent scored on Depression. As with model 1 , our independent variables have materially added to our ability to predict anxiety in teachers. However, the regression coefficients shown in Table 4 demonstrate that three predictors: Workload, Student Behaviour, and Employment Conditions all make statistically and substantively significant contributions to teacher anxiety levels. Indeed, the standardized regression coefficient for Employment Conditions of .232 is the highest of the three statistically significant predictors in the model, and reveals that employment 
concerns such as poor promotion opportunities, job security, lack of professional development, and so forth are the most important determinants of Anxiety in teachers, followed by workload-related and student behaviour stressors. Finally, as in the model for teacher depression, administrative sources of stress contribute little to teacher anxiety and are statistically and substantively insignificant.

Table 4: Multiple Regression: Impact of Workload, Student Behaviour, Employment Conditions, and Administration on Teacher Anxiety.

\begin{tabular}{ccc}
\hline Source of Stress & $\begin{array}{c}\text { Unstandardized } \\
\text { Regression Coefficient }\end{array}$ & $\begin{array}{c}\text { Standardized } \\
\text { Regression Coefficient }\end{array}$ \\
\hline Workload & $.171^{*}$ & $.188^{*}$ \\
Student Behaviour & $.161^{*}$ & $.173^{*}$ \\
Employment Conditions & $.226^{*}$ & $.232^{*}$ \\
Administration & .003 & .003 \\
Constant & $2.182^{*}$ &
\end{tabular}

$* p<.05$, Multiple $\mathrm{R}=.491$, Multiple R-Squared $=.24$

Results of Regression Model 3: Operationalizing Plausible Predictors of Teacher Job Satisfaction

We used the two factor indices from phase one of our results to operationalize the variables of Depression and Anxiety to predict teacher job satisfaction. A third promising predictor of job satisfaction was developed from a Likert-type scale question on the survey which asked respondents "In general, how stressful do you find being a teacher?" The 5 response options ranged from "not at all stressful" to "extremely stressful" and the answers to this question entered our model under the variable name Stress.

To further specify our regression model, a series of "dummy" variables were created as potential covariates of job satisfaction. These dummy variables included Gender and Full / Part-time Position were included as categorical covariates. Finally, Years of Experience (measured on a 9 interval scale ranging from 0-4 years to 40 or more years, and Grade Level (measured on a 6 point scale from $\mathrm{JK} / \mathrm{SK}$ to grades 10-12), were entered as interval predictors in our model. Regression diagnostics available in SPSS Regression revealed that our model did not violate the assumptions of multiple linear regression.

Looking at the overall fit of the model, the multiple correlation coefficient between our seven predictors of teacher job satisfaction was a moderate, statistically significant .510. As a consequence, respondent scores on the variables measuring Stress, Anxiety, Depression, Gender, Full or Part-tem Position, Grade Level, and Years of Experience explained or caused over onequarter $(26 \%)$ of the variability in teacher job satisfaction.

While our independent variables have materially improved our ability to predict job satisfaction among in teachers, examining the parameters in Table 5 reveals that only Stress, Depression, and Years of Experience had statistically significant regression coefficients. In particular, the unstandardized regression coefficient for Stress of -.288 tells us that as respondent scores on job stress increase by one unit, their score on the variable measuring job satisfaction decrease by .288 units. Similarly, the unstandardized coefficient for the factor 
index measuring Depression was -.190. Hence, every one unit increase in depression symptoms leads to a decrease of .190 units in job satisfaction. On the other hand, every one unit increment in Years of Experience, net of the other predictors in the model, led to a .08 unit increase in teacher job satisfaction. The standardized regression coefficients demonstrate the relative importance of each predictor, and confirm that Stress, Depression, and Years of Experience are salient predictors of job satisfaction among educators.

Table 5: Multiple Regression: Impact of Stress, Anxiety, Depression and Employment Conditions on Teacher Job Satisfaction

\begin{tabular}{ccc}
\hline Predictor Variables & $\begin{array}{c}\text { Unstandardized } \\
\text { Regression Coefficient }\end{array}$ & $\begin{array}{c}\text { Standardized Regression } \\
\text { Coefficient }\end{array}$ \\
\hline Anxiety & -.138 & -.130 \\
Depression & $-.190^{*}$ & $-.179^{*}$ \\
Gender & -.045 & -.018 \\
Full-time/Part-time & -.208 & -.085 \\
Years of Experience & $.080^{*}$ & $.121^{*}$ \\
Grade Level & .042 & .067 \\
Constant & 6.233 &
\end{tabular}

$* p<.05$, Multiple $\mathrm{R}=.510$, Multiple R-squared $=.26$

\section{Discussion}

The purpose of the study was to identify which occupational stress factors predict depression and anxiety among teachers and to discover predictors of teacher job satisfaction. The stress factors that we identified in our study (workload, student behaviour for both Depression and Anxiety, and additionally employment conditions for Anxiety) accounted for about $1 / 4$ of the variance in both anxiety and depression. This variance can be attributed to occupational stress, barring other possible contributors to anxiety and depression, such as personal lives or a history of anxiety or depression. Negative occupational stress may lead to depression and anxiety among teachers. We also found that stress and depression are significant and negative predictors of job satisfaction, whereas years of teaching experience is a significant and positive predictor of job satisfaction.

Workload and student behaviour were found to be significant predictors of depression and anxiety. Role ambiguity and role overload may be a root of workload distress (Mirowsky \& Ross, 2003). Although teachers may not have control over workload, clearly, the management of workload is essential for teachers. New curriculum and the implementation of new initiatives may add to a feeling of work overload. Many teachers may have difficulty defining their role and this may lead to stress, as was found by Revicki et al. (1993) in their work with emergency medicine residents and stress. For teachers, workload may be difficult to manage without definitive boundaries and a feeling of there always being work to do. While teachers can manage classrooms, in reality they have little control over individual student behaviour. Employment conditions were also a significant predictor of anxiety among teachers. While job security and opportunities for advancement may be out of a teacher's control, support through 
career counselling and education about teacher collective agreements may help in reducing anxiety.

Although teachers may have little or no control over workload, student behaviour, and working conditions, social supports may ease distress (Chan, 2002; Mirowsky \& Ross, 2003; Revicki et al., 1993). Administrative support and awareness is essential in helping teachers manage workload as well as student behaviour concerns. Having supports in the school for student behaviour issues, a school-based strategy to deal with behaviour, and working with parents of students with behaviour problems may also help reduce stress caused by student behaviour. It is important for teachers to have a support network both inside and outside of school. However, with increased workload, many teachers may feel as though they do not have the time to create and maintain such support systems. As Schonfeld (1990) notes, more research into the role of social supports and teacher stress is needed. To investigate the relationships among stress factors, anxiety, depression, and social supports, we will conduct further data analysis in the future.

While distress may never be totally eliminated, we feel that an informed educational community as well as positive school cultures that acknowledge and support educators may also help alleviate some stress felt by teachers (Mirowsky \& Ross, 2003). Many parents, administrators, and community members may be unaware of the psychological distress faced by educators and the resulting impact on teachers' mental health. In addition, our previous research indicates that among teachers, there is indeed a stigma surrounding teachers stress. We found that the frequency of discussing stress with one's doctor or other teachers increases the probability of a teacher perceiving high levels of stress-related stigma (Ferguson, Frost, Kirkwood, \& Hall, 2007). Thus, for many teachers, there remains shame in discussing stress with one's peers and even with one's primary health care provider. All members of the school community, including teachers and administrators alike, should be able to talk about and express stress in the open without feelings of shame or discredit (Ferguson et al., 2007).

Our finding that stress itself is a significant negative predictor of job satisfaction supports previous research that has found a negative correlation between stress and job satisfaction. Borg and Riding (1991) found this negative relationship between job stress and job satisfaction to be true in their study of Maltese teachers. Manthei and Gilmore (1996), in their study of New Zealand intermediate teachers, also found a positive correlation of $r=.49$ between general stress and job dissatisfaction (Manthei \& Gilmore, p. 7). While stress was a significant negative predictor of job satisfaction in our study, teachers, however, still reported high levels of job satisfaction, with $82 \%$ of respondents stating that they were fairly or very satisfied with their jobs as teachers. This is even a slightly higher job satisfaction level than was found by the Ontario College of Teachers (Browne, 2007). Our study also found that depression was a significant negative predictor of job satisfaction. While this finding may not be surprising, we could find no other published study which reports that depression is a statistically significant predictor of teacher job satisfaction. Given that stress and depression are significant predictors of job unsatisfaction, personal supports should be available for those teachers requiring it. Increasing job satisfaction may also affect levels of stress and depression among teachers. 
The only demographic characteristic we found that significantly predicts job satisfaction is years of experience in teaching. The fact that years of teaching experience is a significant predictor of job satisfaction may have implications for teacher retention initiatives. It appears that with experience, as teachers become more comfortable and capable in their jobs, job satisfaction increases. Alternately, higher job satisfaction in experienced teachers may be an artifact of unsatisfied teachers leaving the profession prematurely, resulting in a larger number of teachers satisfied in the more experienced teachers in our sample. As one participant noted in the open comments section our survey, "I love teaching! It is a very busy job and yes stressful at times - maybe not for everyone, but for me-yes!" This finding supports the report of the Ontario College of Teachers who found that teachers who have left the profession have a lower level of job satisfaction than those who intend to return to teaching. Thus, for teachers who decide to stay in teaching, there may be a learning curve in the teaching profession where teaching becomes more satisfying as teachers gain experience. We believe initiatives such as the mentoring of new teachers and new teacher induction programs may be useful in supporting new teachers as they gain experience early in their careers.

Following our theoretical framework of Herzberg's motivation and hygiene theory (Herzberg, Mausner, \& Snyderman, 1959), stress and depression may be a result of hygiene factors and thus lead to job dissatisfaction. Workload and student behaviour, can both be classified as hygiene factors since they are "conditions which surround the doing of the job" rather than the work related to the task itself (Herzberg, Mausner, \& Snyderman, p. 113). In addition, more experienced teachers may be more likely to have had more opportunities for motivation factors than novice teachers. Opportunities for growth, increased responsibilities, and opportunities for advancement may not occur until after a teacher has had some experience in the profession. More experienced teachers may also be able to focus on the work itself since they have more experience coping with hygiene factors such as classroom management, time management, student behaviour, and workload.

\section{Limitations}

While our study found significant stress predictors of anxiety and depression among teachers, the study does have some limitations. As with any survey research, there is the possibility of social desirability bias and some teachers may feel the need to respond to questions in a particular way. While the return rate for the survey was strong, males were underrepresented in the study, with $17.6 \%$ of respondents being male and $82.4 \%$ being female. As well, many teachers represented a younger age bracket: $43.3 \%$ of the respondents were under the age of 34 and newer teachers also made up the majority of respondents, with $35.3 \%$ having 0 to 4 years experience and $30.1 \%$ having 4 to 9 years experience. Secondary teachers were also underrepresented, with only $16.1 \%$ of the respondents being secondary school teachers compared with $54.9 \%$ being elementary teachers. In addition, because of the varying nature of a teacher's job, other limitations to the study are the time and history threats since a teacher's current assignment, school, class, principal, etc., can change from year to year and, therefore, so can their occupational stress levels and job satisfaction. 


\section{Conclusion}

This study provides a new perspective into teacher stress factors as predictors of depression and anxiety and predictors of teacher job satisfaction not elsewhere discussed in the literature. While the potential risks of a compromised workforce of teachers who are unsatisfied with their jobs and regularly experience anxiety and depression, and its effects on teaching and student achievement are not within the scope of this research, the results of this study, however, have significant implications for all stakeholders in education. We feel, however, that dealing with issues surrounding workload, student behaviour, and employment conditions, may help reduce stress, and thus reduce depression and anxiety among teachers. We believe that dealing with issues surrounding teacher stress and depression and providing supports for new teachers may help increase job satisfaction among teachers. Further research into studying teacher job satisfaction longitudinally is required to investigate how job satisfaction may change over a teachers' career. This further research into job satisfaction would be worthwhile since the high rewards of teaching may appear later in one's career. As one teacher in our study states, "Yes being a teacher could be very stressful at times, but I love teaching. I love being a teacher. It does have its 'rewards'.",

\section{Acknowledgements}

Sections in draft form of this paper have been presented at the 2008 Canadian Society for the Study of Education and the 2008 American Educational Research Association's annual conferences.

\section{Authors' Note}

Our co-author, Dr. David Hall, passed away while this article was in review. We dedicate this article to our colleague and friend.

\section{References}

Baba, V. V., Galperin, B. L., \& Lituchy, T. R. (1999). Occupational mental health: A study of work-related depression among nurses in the Caribbean. International Journal of Nursing Studies, 36(2), 163-169.

Borg, M. G., \& Riding, R. J. (1991). Occupational stress and satisfaction in teaching. British Educational Research Journal, 17(3). 263-281.

Browne, L. (2007). State of the Teaching Profession 2007. Professionally Speaking, September, 4958.

Canadian Teachers' Federation. (2001). Canadian Teachers' Federation June 2001 workplace survey. Retrieved July 7, 2004, from http://www.ctf-fce.ca/en/press/2001/Workplc.htm

Cedoline, A. J. (1982). Job burnout in public education: Symptoms, causes and survival skills. New York, NY: Teachers College.

Chan, D. W. (2002). Stress, self-efficacy, social support, and psychological distress among prospective Chinese teachers in Hong Kong. Educational Psychology, 22(5), 557-569.

Decker, F. H. (1997). Occupational and nonoccupational factors in job satisfaction and psychological distress among nurses. Research in Nursing and Health, 20(5), 453-564.

DeFrank, R. S. \& Stroup, C. A. (1989). Teacher stress and health; An examination of a model. Journal of Psychosomatic Research, 33(1), 99-109. 
EdudataCanada. (n.d.). Teacher stress. Retrieved July 2, 2004, from http://www.edudata.educ.ubc.ca/Data Pages/BCTF/teacher\%20stress.htm

Evans, V. \& Johnson, D. J. (1990). The Relationship of principals' leadership behavior and teachers' job satisfaction and job-related stress. Journal of Instructional Psychology, 17(1), 11-19.

Ferguson, K., Frost, L., Kirkwood, K., \& Hall, D. (2007). Teacher stress and stigma in northern Ontario. In J.A. LeClair \& L.T. Foster (Eds.), Contemporary Issues in Mental Health: Concepts, Policy, and Practice. (pp. 211-225). Victoria, BC: Western Geographical Press.

Fimian, M. J. (1984). The development of an instrument to measure occupational stress in teachers: The teacher stress inventory. Journal of Occupational Psychology, 57(4), 277-293.

Flanagan, N. A. (2006). Testing the relationship between job stress and satisfaction in correctional nurses. Nursing Research, 55(5), 316-327.

Gelsema, T. I., Van Der Doef, M., Maes, S., Janssen, M., Akerboom, S., \& Vergoeven, C. (2006). A longitudinal study of job stress in the nursing profession: Causes and consequences. Journal of Nursing Management, 14(4), 289-299.

Jamieson, B. (2006). State of the teaching profession 2006: Back in the day... Retrieved October 10, 2006, from http://www.oct.ca/publications/professionally_speaking/september_2006/survey.asp

Herzberg, F., Mausner, B., \& Snyderman, B. B. (1959). The Motivation to work (2 ${ }^{\text {nd }}$ ed). New York, NY: Wiley \& Sons.

Kim, I. \& Loadman, W. E. (1994). Predicting Teacher Stress. The Ohio State University. Retrieved October 1, 2007, from the ERIC database. (ERIC Document Reproduction Service No. ED283707).

Kyriacou, C. (2001). Teacher stress: Directions for future research. Educational Review, 53(1), $27-$ 35.

Kyriacou, C., \& Sutcliffe, J. (1978). Teacher stress: Prevalence, sources, and symptoms. British Journal of Educational Psychology, 48, 159-167.

Littrell, P. C. (1994). The Effects of principal support on special and general educators' stress, job satisfaction, school commitment, health, and intent to stay in teaching. Remedial and Special Education, 15(5), 297-310.

Manthei, R., \& Gilmore, A. (1996). Teacher stress in intermediate schools. Educational Research, 28(1), 3-19.

McIntryre, F. (2006). Ontario grads stay with teaching. Professionally Speaking, June, 47-50.

Ministry of Education. (n.d.). School board profiles. Retrieved October 30, 2005, from http://esip.edu.gov.on.ca/english/default.asp

Mirowsky, J., \& Ross, C.E. (2003). Social causes of psychological distress $\left(2^{\text {nd }}\right.$ ed). Hawthorne, NY: Aldine De Gruyther.

Nias, J. (1981). Teacher Satisfaction and Dissatisfaction: Herzberg's "Two-Factor" Hypothesis Revisited. British Journal of Sociology of Education, 2(3), 235-246.

Revicki, D. A., Gallery, M. E., Whitley, T. W., \& Allison, E. J. (1993). Impact of work environment characteristics on work-related stress and depression in emergency medicine residents: A longitudinal study. Journal of Community and Applied Social Psychology, 3(4), 273-284.

Rout, U. R. (2000). Stress amongst district nurses: A preliminary investigation. Journal of Clinical Nursing, 9(2), 303-309.

Schonfeld, I. S. (1990). Psychological distress among a sample of teachers. The Journal of Social and Psychological Foundations, 124(3), 321-38.

Selye, H. (1976). The stress of life (Rev. ed.). New York, NY: McGraw-Hill.

Tabachnick, B. G., \& Fidell. L. S. (2007). Using multivariate statistics $\left(5^{\text {th }}\right.$ ed.) Toronto, Canada: Pearson.

Taylor, D. L. \& Tashakkori, A. (1995). Decision participation and school climate as predictors of job satisfaction and teachers' sense of efficacy. Journal of Experimental Education, 63(3), 217-231. 
Kristen Ferguson is an assistant professor of Language Arts and Literacy in the Schulich School of Education at Nipissing University.

Lorraine Frost is an associate professor of Educational Psychology and Special Education in the Schulich School of Education at Nipissing University.

David Hall was an associate professor in the Department of Sociology at Nipissing University.

Please address correspondence to Kristen Ferguson: kristenf@nipissingu.ca 